\title{
Microscopic emphysema in relation to age and smoking habit
}

\author{
M Gillooly, D Lamb
}

\begin{abstract}
Background-The increases in airspace size within the human lung associated with microscopic emphysema can be assessed by measuring the airspace wall surface area per unit volume of lung tissue (AWUV). In a previous study the limits of normality of AWUV with age were estimated in lifelong non-smokers by the $95 \%$ prediction limits of the regression line for these variables. The aims of this study were to study the incidence of microscopically assessed emphysema in a group of smokers and to examine the influence of smoking habit on the susceptibility to and severity of
\end{abstract} microscopically assessed emphysema.

Methods-AWUV was measured on tissue sections from 125 lung specimens obtained from tobacco smokers (mean age $61 \cdot 1$ (range 33-85) years) with the fast interval processor, a rapid automatic scanning device. The mean AWUV value was calculated for each specimen and this figure was plotted against the age of the subject. The limits of normal AWUV were plotted, and AWUV values below these limits were taken as indicative of microscopically assessed emphysema. Details of the number of cigarettes smoked each day were obtained for 97 of the smokers. These subjects were grouped according to smoking habit: group 1, 1-19 cigarettes/day; group 2, 20-29 cigarettes/day; group 3, at least 30 cigarettes/day. The AWUV results from each of these groups were then assessed.

Results-Mean AWUV decreased with age in this group of smokers, but only $26 \%$ had microscopically assessed emphysema, indicating that within the group there were two subgroups of smokers with differing susceptibility to microscopically assessed emphysema. There were no sex differences in the incidence of microscopically assessed emphysema, nor were the incidence and severity increased with increased daily cigarette consumption.

Conclusions-Susceptibility to microscopically assessed emphysema was found to be similar in male and female smokers. Daily cigarette consumption did not appear to be the primary factor influencing the susceptibility to or severity of microscopically assessed emphysema. Susceptibility differences within the smoking population should be taken into consideration in studies of the pathogenesis of emphysema.

(Thorax 1993;48:491-495)

Various definitions of pulmonary emphysema have been proposed, ${ }^{1-4}$ all of which include reference to the abnormal enlargement of airspaces distal to the terminal bronchiole. The accurate diagnosis of emphysema in pathological specimens has been difficult because, although normal airspace size is thought to be in the region of $250 \mu \mathrm{m},{ }^{56}$ until recently the limits of normality of airspace size have been undefined.

In most previous studies the presence and extent of emphysema has been assessed by examining whole slices of fixed inflated lung specimens, where airspaces larger than $1 \mathrm{~mm}$ in diameter were considered emphysematous. Macroscopic techniques are insensitive to the early stages of the disease, when although the airspaces have become enlarged, the average diameter is still less than $1 \mathrm{~mm},{ }^{7}$ but they are sensitive to focal abnormalities-for example, centriacinar emphysema or foci of paraseptal emphysema, which may be visible in a lung with otherwise normal airspaces.

As noted previously, ${ }^{8}$ many of the microscopic techniques available for assessing emphysema have been subjective. Objective, quantitative techniques such as mean linear intercept $(\mathrm{Lm})$ have been limited in their usefulness in identifying early emphysema by the absence of baseline data. We believe that objective, quantitative methods should be used in the study of early (microscopic) emphysema, and that airspace size should be measured. Airspace size can be quantified indirectly by measuring airspace wall surface area. We have developed a rapid automated technique for measuring airspace wall surface area per unit volume of lung tissue (AWUV).$^{8}$

In a recent study we found a linear decline in mean AWUV with advancing age in 38 adult lifelong non-smokers, indicating an increase in airspace size with age. ${ }^{9}$ The limits of normality for mean AWUV were established from the $95 \%$ prediction limits of the regression line relating mean AWUV to age. A generalised increase in airspace size within

\footnotetext{
Received 21 September 1992 Returned to authors Revised version received 17 December 1992

Accepted 24 December 1992

Department of of Edinburgh Medical M Gillooly

D Lamb
} 
a lung is reflected in a decrease in the mean AWUV for that lung. We suggested that mean AWUV values below the $95 \%$ prediction limits were considered indicative of emphysema, and that the emphysema detected by measuring changes in AWUV should be called microscopically assessed emphysema.

The aims of this study were (1) to measure AWUV in the lungs of a group of smokers and to observe the relationship between mean AWUV and age in these smokers; (2) to observe the incidence of microscopically assessed emphysema in this group; (3) to examine the sex differences in the incidence of microscopically assessed emphysema; and (4) to examine the effect of smoking habit on the development of microscopically assessed emphysema.

\section{Methods}

STUDY SAMPLE

Lung specimens from 125 smokers were included in the study. This sample included complete lungs obtained at necropsy from 26 subjects, and 99 lobes obtained by surgical resection for treatment of a peripheral tumour. In our recent study of whole lung specimens obtained at necropsy we found that, in the absence of severe macroscopic emphysema, there was no apex to base variation in AWUV values within individual lobes, and there were no differences in mean AWUV between the upper and lower lobes. ${ }^{10}$ We have also found that, when microscopically assessed emphysema was present, its incidence was similar in the upper and lower lobes of the lungs (unpublished observation). We are therefore satisfied that AWUV measurements from a single lobe may be accepted as representative of the whole lung.

There were 95 men and 30 women in the sample, whose ages ranged from 33 to 85 years (mean $61 \cdot 1$ years). Smoking histories were obtained from interviews with clinicians before referral for surgery, and those of the necropsy cases were recorded at interviews with relatives at the time of death, or obtained from clinical records. Data were not collected in a way which allowed pack years to be calculated.

The smokers were divided into four groups on the basis of their smoking habit: group 1, 1-19 cigarettes per day; group 2, 20-29 cigarettes per day; group 3, 30 or more cigarettes per day; group 4, cigar or pipe smokers. Twenty six specimens were retained from a group of cases where details of the smoking habit were limited. These specimens were included in all the analyses described below, except analyses relating to daily tobacco consumption.

TISSUE PROCESSING AND SAMPLING

Lungs or lobes were inflated intrabronchially with $10 \%$ buffered formalin at a pressure of $25 \mathrm{~cm} \mathrm{H}_{2} \mathrm{O}$ and fixed in $10 \%$ buffered formalin for a minimum of 24 hours. Following complete fixation they were cut into $1 \mathrm{~cm}$ parasagittal slices. A minimum of six $2 \mathrm{~cm} \times$ $2 \mathrm{~cm}$ blocks were selected from the mid sagittal slice in the necropsy specimens, and from the lateral two subpleural slices in the surgical specimens, as described previously. ${ }^{9}$ The blocks were processed in glycol methacrylate resin, and a $3 \mu \mathrm{m}$ histological section stained with haematoxylin and eosin was taken to represent each block.

\section{MEASUREMENT OF AWUV}

Each tissue section was scanned with the fast interval processor (FIP) automated scanning system $^{8}$ to measure the mean linear intercept $(\mathrm{Lm})$. AWUV was then calculated using the formula AWUV $=2 / \mathrm{Lm} .{ }^{8}$ The mean AWUV (expressed in $\mathrm{mm}^{2} / \mathrm{mm}^{3}$ ) was then calculated for each specimen.

\section{DATA ANALYSIS}

The mean AWUV was plotted against age for the 125 smokers. The Spearman correlation coefficient for the AWUV-age relationship was calculated. The limits of normal AWUV, derived in our recent study, ${ }^{9}$ were plotted to allow the assessment of the incidence of microscopically assessed emphysema in this sample of smokers.

The regression equations for the AWUV-age relationships in the men and women were calculated, and multiple regression analysis was performed in an attempt to identify any sex differences.

The severity of microscopically assessed emphysema was assessed by expressing the mean AWUV from each lung specimen as a percentage of the value of the lower limit of normal AWUV for the subject's age. A percentage value of 100 or more therefore indicated an AWUV at or above the lower limit for the subject's age, and lungs with microscopically assessed emphysema had AWUV values which were less than $100 \%$ of the lower limit.

\section{Results}

AWUV decreased with advancing age, indicating that airspace size increased with age (fig 1). The rate of decline of AWUV with age was the same for both men and women (men: AWUV $=23-0.13 \mathrm{AGE}$; women: AWUV $=24 \cdot 1-0 \cdot 13 \mathrm{AGE}$ ). Multiple regression analysis confirmed that sex was not an influential factor in the AWUV-age relationship.

Only $33(26 \%)$ of these smokers had mean AWUV values below the normal range for their age-that is, microscopically assessed emphysema (fig 1). In those smokers with normal mean AWUV values, the AWUV-age relationship was almost identical to that found in our previous study of 38 lifelong non-smokers (AWUV $=23 \cdot 1-0.09 \mathrm{AGE}$ in non-smokers; AWUV $=22 \cdot 7-0.095 \mathrm{AGE}$ in smokers with normal mean AWUV). These results show that within the group of smokers there existed two subgroups with differing susceptibility to microscopically assessed emphysema. 


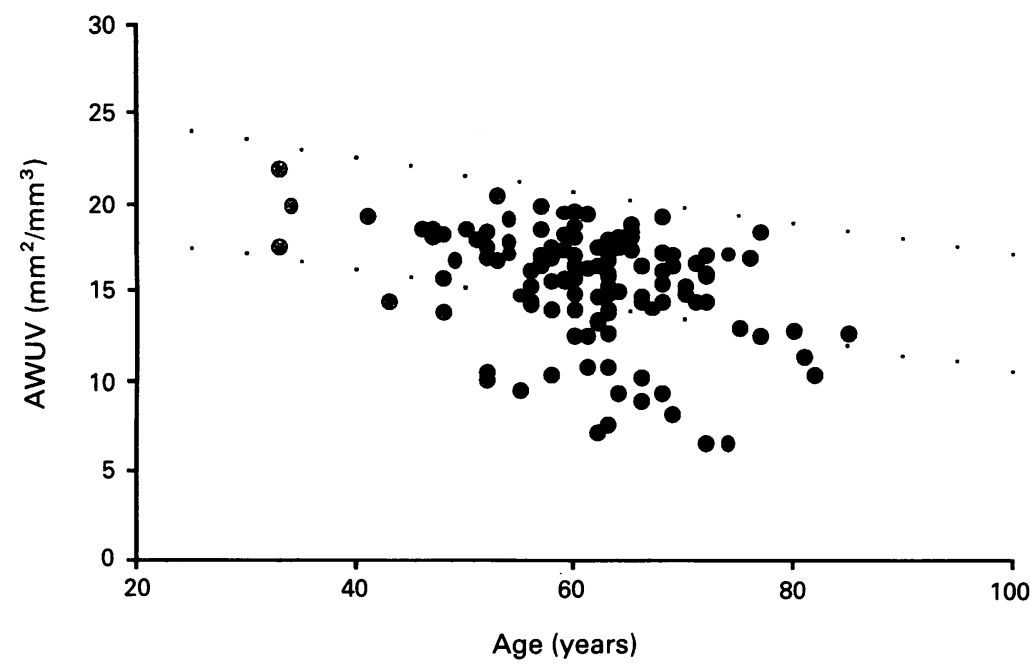

Figure 1 Relationship between AWUV (O) and age in lung specimens from 125 smokers. The upper and lower limits of normal mean AWUV (•) are shown. This graph illustrates that only $26 \%$ of the smokers had mean AWUV values which were below the normal limits.
Figure 2 Mean AWUV plotted against age in men (O) and women (O) showing upper and lower limits of normal mean $A W U V(\bullet)$. The relationship between $A W U V$ and age was similar for both sexes, with similar proportions of the male and female groups showing microscopically assessed emphysema.

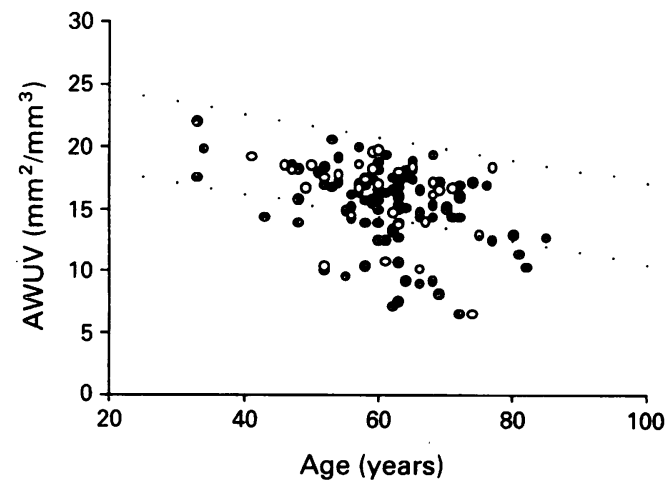

Figure 3 Mean AWUV plotted against age for each of the three groups of cigarette smokers showing upper and lower limits of normal mean $A W U V$

(०); 0, group 1 (1-19 cigarettes per day); $\mathrm{O}$, group 2 (20-29 cigarettes per day); $\square$, group 3 (30 or more cigarettes per day). Individuals with microscopically assessed emphysema came from all three groups.

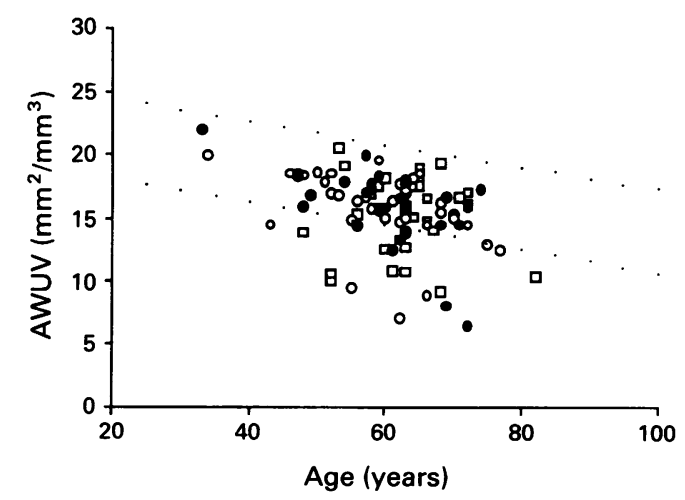

Results in each of the groups of cigarette smokers

\begin{tabular}{llll}
\hline & $\begin{array}{l}\text { Normal mean } \\
\text { AWUV }\end{array}$ & $\begin{array}{l}\text { Microscopically } \\
\text { assessed emphysema }\end{array}$ & Total \\
\hline $\begin{array}{l}\text { Group 1 } \\
\text { (1-19 cigarettes/day) }\end{array}$ & 20 & 6 & 26 \\
$\begin{array}{l}\text { Group 2 } \\
\text { (20-29 cigarettes/day) }\end{array}$ & 31 & 8 & 39 \\
$\begin{array}{l}\text { Group 3 } \\
\text { (30 or more cigarettes/day) }\end{array}$ & 22 & 10 & 32 \\
Total & 73 & 24 & 97 \\
\hline
\end{tabular}

The proportions of the three groups with microscopically assessed emphysema were similar $\left(\chi^{2}=1 \cdot 14, \mathrm{NS}\right)$, indicating that daily cigarette consumption was not the primary factor in susceptibility to microscopically assessed emphysema.

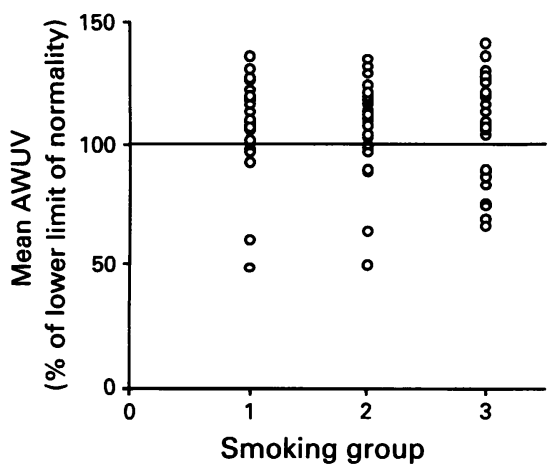

Figure 4 Mean AWUV expressed as a percentage of the value for the lower limit of normal mean $A W U V$ in the three groups; group 1, 1-19 cigarettes per day; group 2, 20-29 cigarettes per day; group 3, 30 or more cigarettes per day. The horizontal line represents the lower limit of normal mean AWUV. Points below this line represent microscopically assessed emphysema. The graph indicates that the severity of microscopically assessed emphysema was not related to daily cigarette consumption.

Similar proportions of the male and female subgroups of smokers developed microscopically assessed emphysema ( $27 \%$ of the males, $23 \%$ of the females; fig 2 ). This indicates that there were no sex differences in the susceptibility to microscopically assessed emphysema.

Only two of the subjects in this study were pipe or cigar smokers, and one of these had microscopically assessed emphysema. We cannot draw any conclusions on the effect of pipe or cigar smoking on the development of microscopically assessed emphysema from this result.

Details of the number of cigarettes smoked each day were available for 97 subjects. Of these, 26 smoked 19 or fewer cigarettes (group 1), 39 smoked between 20 and 29 cigarettes (group 2), and 32 subjects smoked 30 or more cigarettes each day (group 3 ). When mean AWUV was plotted against age for these 97 individuals, 24 (25\%) were found to have microscopically assessed emphysema (fig 3). The subjects with microscopically assessed emphysema came from all three groups (fig 3), and although a greater proportion of group 3 had microscopically assessed emphysema, the differences in incidence between the groups were not significant $\left(\chi^{2}=1 \cdot 14\right)($ table)

When the AWUV values were expressed as a percentage of the lower limit of the normal range of AWUV, similar ranges of values were found in all three groups of cigarette smokers (fig 4). This result indicates that in the smokers studied the severity of microscopically assessed emphysema did not increase with increased daily cigarette consumption.

\section{Discussion}

Although the definitions of emphysema refer to the abnormal enlargement of airspaces, the range of normal airspace size remained undefined until our recent study in which we also described microscopically assessed emphysema as a condition where mean AWUV 
values are below the normal range. 9 The reduction in mean AWUV in a lobe or a lung will reflect a generalised increase in the airspace size within that specimen. Microscopically assessed emphysema must, therefore, reflect panacinar rather than centriacinar emphysema.

Only $26 \%$ of the smokers in this study had microscopically assessed emphysema, and the AWUV-age relationship in smokers with normal mean AWUV values was found to be almost identical to that found previously in a group of 38 lifelong non-smokers. This indicates that smoking is not the only factor responsible for the onset of microscopically assessed emphysema, and that those individuals with microscopically assessed emphysema may have an inherent susceptibility to the disease. Differences in susceptibility to macroscopic emphysema and to chronic airflow obstruction have frequently been noted in the literature, and this subject has been reviewed by Sobonya and Burrows. ${ }^{11}$ It has been suggested that the susceptibility to macroscopic emphysema, in particular centriacinar emphysema, in smokers is related to sex ${ }^{11-14}$ and is dose related with respect to smoking habit. ${ }^{11} 15$

We found that there were no sex differences in the susceptibility to microscopically assessed emphysema. This is an interesting observation, since macroscopic emphysema has consistently been found to be more common in men, ${ }^{16}{ }^{17}$ and it has even been suggested that women may have some protective factor against developing the disease. ${ }^{16}{ }^{18}$ Our findings suggest that this is not the case with microscopically assessed emphysema. These results indicate that there may be differences in the pathogenetic mechanisms responsible for microscopically assessed emphysema and those related to the most common form of macroscopic emphysema, centriacinar emphysema. It has been suggested that different pathogenetic mechanisms are involved in the onset of centriacinar and panacinar emphysema $a^{12} 151920$ and, as mentioned above, it is likely that the microscopic form studied here is more closely related to and reflects the presence of panacinar rather than centriacinar emphysema. This will be the subject of a future publication.

Several workers have found the relative incidence of macroscopic emphysema to be increased with increased tobacco consumption. ${ }^{162122}$ Pride noted that the most obvious potential cause for the differing susceptibility to chronic airflow obstruction in smokers (which may be related to emphysema) is differences in exposure to tobacco smoke..$^{23} \mathrm{We}$ were interested to examine the relationship between smoking habit-that is, exposure to tobacco smoke-and the susceptibility to microscopically assessed emphysema in order to investigate whether susceptibility was related to dose.

We found that the differences in susceptibility to microscopically assessed emphysema observed in our study group did not appear to be due to differences in smoking habit. Daily cigarette consumption was therefore not the primary factor in determining an individual's susceptibility. In addition, the severity of microscopically assessed emphysema was not related to daily cigarette consumption.

Tobacco consumption was assessed by recording the number of cigarettes smoked each day. Daily cigarette consumption was a more appropriate measure of tobacco dosage for the purposes of this study than pack years. This is because both pack years and AWUV are related to the subject's age, and thus the true relationship between the degree of tobacco consumption and AWUV would be confused by the effect of age.

It is accepted that smoking histories obtained by interviews with patients (including estimates of pack years) are subject to inaccuracies. When questioned, many patients underestimate their tobacco consumption. ${ }^{24}$ Nevertheless, the three broad groups of smoking habit selected for this study represent a range of tobacco consumption from light to severe.

Given that inaccuracies in smoking habit information do occur, we would expect that the subjects in all three groups will have underestimated the extent of their actual smoking habit, and yet even in the group of heaviest smokers, $69 \%$ of subjects had normal AWUV values for their age. It would therefore appear that, while smoking is undoubtedly related to the onset of microscopically assessed emphysema, smoking habit is not the major factor in determining an individual's susceptibility, or in determining the severity of microscopically assessed emphysema which susceptible individuals will develop.

Several authors have previously commented on differences in susceptibility to emphysema and related conditions in smokers. Anderson et al suggested that, since large numbers of individuals with heavy tobacco consumption did not develop macroscopic emphysema, the variations in susceptibility to the disease were not accounted for by smoking habit alone. ${ }^{15}$ Pratt has also noted differences in susceptibility to centriacinar emphysema amongst heavy smokers, ${ }^{25}$ and Pride has stated that wide differences in susceptibility to airflow obstruction in smokers are not explained by variations in dose of smoke. ${ }^{23}$

We feel that the percentage of our study group with microscopically assessed emphysema may not reflect the true incidence in the general population as our sample was subject to selection factors, in particular the fact that the majority of the specimens were obtained from surgical resections for treatment of lung cancer. It is possible, since lung cancer and emphysema are both associated with tobacco smoking, that the susceptibility factors responsible for these conditions may be related, and this could have affected the observed incidence of microscopically assessed emphysema. Furthermore, the subjects had to be fit enough to undergo major surgery and had to have adequate pulmonary function. Although the smokers came from a wide age range 
(33-85 years), most ( $86 \%$ ) of the subjects were between 50 and 70 years (mean age 61.1 years). It is apparent from the results presented here, however, that the susceptibility to microscopically assessed emphysema is similar in men and women and is related to tobacco smoking. Daily cigarette consumption does not, however, appear to be the most influential factor in the susceptibility to and severity of microscopically assessed emphysema.

Most studies of the pathogenesis of emphysema fail to recognise that smokers are not a homogeneous group. The results presented in this paper indicate that differences in susceptibility within the smoking population must be recognised before the pathogenesis of the various forms of emphysema can be fully understood.

This study was supported by the Norman Salvesen Emphysema Research Fund.

1 Ciba. Terminology definitions and classification of chronic pulmonary emphysema and related conditions. Thorax 1959;14:286-99.

2 American Thoracic Society. Statement on definitions and classification of chronic bronchitis, asthma, and pulmonary emphysema. Am Rev Respir Dis 1962;85:762-8.

3 Reid L. The pathology of emphysema. London: Lloyd-Luke, 1967:1-5.

4 Snider GL, Kleinerman J, Thurlbeck WM. The definition of emphysema. Report of a National Heart, Lung and Blood Institute, division of lung diseases, workshop. $\mathrm{Am}$ Rev Respir Dis 1985;132:182-5.

5 Weibel ER. Morphometry of the human lung. Berlin: Springer-Verlag, 1963.

6 Schreider JP, Raabe OG. Structure of the human respiratory acinus. Am f Anat 1981;162:221-32.

7 Lamb D. Chronic obstructive pulmonary disease (COPD): pathology. In: Brewis RAL, Gibson GJ, Geddes DM, eds. Respiratory medicine. London: Ballière Tindall, 1990:497-506.

8 Gillooly M, Lamb D, Farrow ASJ. New automated technique for the assessment of emphysema on histological sections. F Clin Pathol 1991;44:1007-11.

9 Gillooly M, Lamb D. Airspace size in lungs of lifelong non-smokers: the effect of age and sex. Thorax 1993;48: $39-43$

10 Lamb D, Gillooly M, Farrow ASI Microscopic emphysema and its variations with age, smoking and site within the lungs. Ann NY Acad Sci 1991;624:339-41.

11 Sobonya RE, Burrows B. The epidemiology of emphysema. Clin Chest Med 1983;4:351-8.

12 Thurlbeck WM. The incidence of pulmonary emphysema, with observations on the relative incidence and spatial distribution of various types of emphysema. Am Rev Respir Dis 1963;87:206-15.

13 Thurlbeck WM. Pulmonary emphysema. Am f Med Sci 1963;246:332-53.

14 Snider GL. Chronic obstructive pulmonary disease: risk factors, pathophysiology and pathogenesis. Ann Rev Med 1989;40:411-29.

15 Anderson AE Jr, Hernandez JA, Holmes WL, Foraker AG. Pulmonary emphysema: prevalence, severity and anatomical patterns in macrosections with respect to smoking habits. Arch Environ Health 1966;12:569-77.

16 Thurlbeck WM, Ryder RC, Sternby N. A comparative study of the severity of emphysema in necropsy populations in three different countries. Am Rev Respir Dis 1974;109:239-48.

17 Sutinen S, Vaajalahti P, Paakko P. Prevalence, severity and types of pulmonary emphysema in a population of deaths in a Finnish city. Correlation with age, sex and smoking. Scand $\mathcal{F}$ Respir Dis 1978;59:101-15.

18 Bignon J, Lenfant C, Scarpa GL. Emphysema: past, present and future. Bull Eur Physiopathol Respir 1980; 16(Suppl 4):423-8.

19 Mitchell RS, Silvers GW, Goodman N, Dart G, Maisel JC. Are centrilobular and panlobular emphysema two different diseases? Human Pathol 1970;1:433-41.

20 Sweet HC, Wyatt JP, Fritsch AJ, Kinsella PW. Panlobular and centrilobular emphysema: correlation of clinical findings with pathological patterns. Ann Intern Med 1961;55:565-81.

21 Auerbach O, Hammond EC, Garfinkel L, Benanta C. Relation of smoking and age to emphysema. Wholelung section study. N Engl f Med 1972;286:853-7.

22 Spain DM, Siegel H, Bradess VA. Emphysema in apparently healthy adults. Smoking, age and sex. $\mathscr{F} A M A$ 1973;224:332-5.

23 Pride NB. Which smokers develop progressive airflow obstruction? Eur $\mathcal{f}$ Respir Dis 1983;64(Suppl 126): 79-83.

24 Viegi G, Paoletti P, Vellutini M, Carrozzi L, Di Pede F, Baldacci $S$, et al. Effects of daily cigarette consumption on respiratory symptoms and lung function in a general population sample of North Italian men. Respiration 1991;58:282-6.

25 Pratt PC. Emphysema and chronic airways disease. In: Dail DH, Hammer SP, eds. Pulmonary pathology. New York: Springer-Verlag, 1988:651-69. 